\title{
Sobe o pano: dicionário de autores dramáticos do Rio Grande do Sul contribui para a história da literatura
}

\author{
Behind the curtain: dictionary of dramatic author's from \\ Rio Grande do Sul contributes to literary history
}

Natasha Centenaro ${ }^{1}$

Mestre em Letras, área de concentração: Escrita Criativa, pela Pontifícia Universidade Catolica do Rio Grande do Sul (PUCRS), bolsista CAPES. Doutoranda em Letras, ărea de concentraçao: Teoria da

natasha centenaro@acad pucrs.br
RESUMO: Este trabalho tem por objetivo apontar considerações sobre a literatura dramática gaúcha a partir da recente publicação de Antenor Fischer em formato de dicionário. Ao reunir verbetes de autores e autoras de textos teatrais, desde o século XIX até o começo do século XXI, Fischer reflete acerca da contribuição do gênero dramático na construção e consolidação da produção literária e teatral do Estado. Tendo em vista, como argumenta o pesquisador, de que esse gênero parece estar relegado a um "segundo plano" nas historiografias literárias, faz-se necessário não apenas a sua inclusão, como também assegurar a sua importância ao evidenciar, dentre outros aspectos, a repercussão da temática abolicionista no bojo da sociedade oitocentista e o expressivo espaço da comédia nos teatros gaúchos, bem como, as mudanças de um período 'textocêntrico' para um teatro de encenador e suas características performáticas nos séculos XX e XXI. Dessa forma, pretende-se, através de uma leitura minuciosa, apresentar e, assim, contemplar o Dicionário de autores da literatura dramática do Rio Grande do Sul (2014) como sendo uma obra significativa para a história da literatura.

Palavras-chave: História da literatura; Literatura dramática; Dicionário de autores da literatura dramática do Rio Grande do Sul; Antenor Fischer.

ABSTRACT: This paper aims on considerations about gaúcha dramatic literature since Antenor Fischer's recent publication in the form of a dictionary. When gathering entries of authors of theatrical texts, from XIX until early XX century, Fischer reflects on the contribution of the dramatic genre in the construction and consolidation of the literary and theatrical productions of the State. With that in view, as the researcher arguments, that this genre appears to be in a "second plain" in the literary historiographies, it becomes necessary not only it's inclusion, but also to assure it's importance when it evidences, among other aspects, the repercussion of the abolition theme in the scope of the eighteenth-hundred's society and the expressive space taken by comedy in gaúcho theaters, as well as the changes, of a 'text-centered' period to a staging-theater period and it's performance characteristics of the XX and XXI centuries. This way, it is intended, through a thorough reading, present, and thus, contemplate the Dicionário de autores da literatura dramática do Rio Grande do Sul (2014) as a significative work to literary history.

KEYwoRDS: Literary history; Dramatic reading; Dicionário de autores da literatura dramática do Rio Grande do Sul; Antenor Fischer. 


\section{Introdução: sobe o pano}

teatro, sendo uma das manifestações artístico-culturais de presença significativa em diferentes sociedades, percorreu períodos históricos, adquiriu funções (da pedagogia coletiva da polis à fruição da arte pela arte, do entretenimento até a reflexão social), combinou aspectos (elementos sígnicos da encenação como cenografia, iluminação e trilha sonora; da performance ou da dramaturgia) assumiu estéticas, enfim, modificou-se. Entretanto, não deixou de representar e evidenciar a cultura do homem de seu tempo. Desde a Antiguidade, em seu caráter mítico-religioso; passando pelo teatro medieval; durante o Renascimento, com o teatro elisabetano inglês, a commedia dell'arte na Itália, a idade de ouro dos teatros espanhol e francês; o período barroco; o teatro do romantismo; as tendências realista e naturalista; o teatro épico, de Bertolt Brecht, no século XX; o teatro do absurdo, de Samuel Beckett, e o pós-dramático do final do século XX, até se alcançar o teatro contemporâneo e os processos colaborativos. A tríade ator-texto-público (questionada e questionável, sobretudo desde a modernidade, especialmente pela necessidade do texto em cena) transforma o espetáculo cênico em um instrumento de propagação social e cultural, bem como é capaz de sustentar todo um processo de comunicabilidade entre suas instâncias constitutivas.

Nesse sentido, o teatro se apresenta como um fazer coletivo (do autor ao diretor ao ator ao cenotécnico, etc.) e uma prática que envolve mecanismos diretos de interação (palco-plateia e suas múltiplas relações). Sendo assim, é possível de se pensar na diferença entre o texto dramático (incluído nos gêneros literários) e o texto narrativo ou poético, por exemplo. Na literatura tradicional, tanto o gênero épico (aqui ampliado e entendido como narrativa em prosa - romance, conto, novela), quanto o gênero lírico comunicam-se inteiramente com o público através do seu próprio suporte ou plataforma.
O gênero dramático (também o texto), por sua vez, complementa-se com a representação, a encenação, o espetáculo. 0 livro que foi publicado pode ficar na estante, ou sendo livro digital. A peça de teatro, por outro lado, não se restringe à escrita e a publicação, seja ela em qualquer formato. De acordo com Anne Ubersfeld (2010, p. 2), em Para ler o teatro, o teatro é:

(...) a própria arte do paradoxo, a um só tempo produção literária e representação concreta; arte a um só tempo eterna (indefinidamente reprodutível e renovável) e instantânea (nunca reprodutível como idêntica a si mesma): arte da representação que é de um dia e nunca a mesma no dia seguinte; quando muito, arte feita para uma única representação.

A autora fala, com isso, do duplo caráter do teatro: texto literário - dramático - e encenação. Para Ubersfeld (2010), a atividade teatral se apresenta de modo que o psiquismo individual está investido numa relação coletiva, o ator nunca está sozinho, assim como o público. Por isso, a essencialidade paradoxal do teatro de um homem só, um único criador, ao pensarmos no teatro de Sófocles, teatro de Eurípides, teatro de Shakespeare, teatro de Molière, teatro de Brecht, mas feito, tão e somente, de modo coletivo por uma equipe de produção.

De acordo com Jacó Guinsburg (2004, p. 6), a atividade teatral se formou através da pluralidade de seus meios e estratos de origem, "ao longo de um eixo de produção simbólica e ficcional que fala de uma criativa e ramificada atividade representificadora do imaginário". Guinsburg (2004) evidencia que a linguagem do teatro se desenvolveu pela via culta, ou seja, a que reproduz a cena literário-dramática e de pesquisas artísticas, e que isso se transformou numa revolução de conceitos que fundamentaram o espetáculo. Nesse sentido, em termos de invenção e sistematização dramático-cênica, tanto o modelo de teatro desenvolvido no Ocidente, quanto no Oriente, guardam elementos em comum, especialmente no que se refere a certo 
operador estético fundamental que é o tratamento da matéria cênica como teatralidade.

[Sic] Para tanto concorrem concepções como as do instinto teatral de Evrêinov ou as da alquimia do teatro de Artaud, conjugadas com as pesquisas dos esteticismos simbolistas à la Gordon Craig, dos funcionalismos construtivistas [sic] à la Meierhold, dos naturalismos e organicismos à la Stanislávski ou das linguagens do Nô, do Kabuki, do Khatakali e da ópera de Pequim que vêm marcando as correntes da encenação contemporânea - de Grotóvski e do Living Theater, de Peter Brook e T. Kantor até Bob Wilson, Pina Bausch e o teatro antropológico de Eugênio Barba ou, no Brasil, as embalagens de Antunes Filho e as filtragens de Gerald Thomas, para citar alguns. Incorporando as descobertas representacionais no plano physis e da psyché, da mentalidade coletiva e da subjetividade individual, em termos de invenção e sistematização dramáticocênica, propondo o seu reprocessamento em novas matrizes imagísticas e estilísticas, em novas simbioses de gêneros e procedimentos, redimensionando as relações de valor dos códigos teatrais e, nelas, as relações de prevalência entre logos e mythos, tais formulações foram, a par de sua significação nos movimentos e nas correntes artísticas a que se prendem, outros tantos agentes dessa nova e expandida percepção de teatro. (GUINSBURG, 2004, p. 6)

A introdução acima foi feita tendo em vista a necessidade de se amparar uma das questões fundamentais na qual está inserida a obra aqui estudada: a importância de se registrar a literatura dramática, e seus autores, como pertencentes ao gênero dramático (gênero literário e prática teatral), mas igualmente incorporada ao campo da história da literatura. Este também foi um dos motivos que levou Antenor Fischer (como ele próprio se descreve: profissional e amante do teatro ${ }^{1}$ ) a realizar em âmbito de

1 "A razão principal que nos levou a propor, ao Programa de Pós-Graduação em Letras da UFRGS, em janeiro de 2010, a execução deste projeto, continuou sendo, a mesma que nos impulsionou a desenvolver, anteriormente, as pesquisas que resultaram nos estudos acima mencionados, ou seja: a de, como profissional e amante do teatro, ver suprida uma lacuna incômoda no campo da historiografia literária sul-rio-grandense, já que, nos estudos que a compõe, como veremos adiante, o gênero dramático é, geralmente, esquecido ou relegado a plano secundário. (FISCHER, Antenor. Dicionário de autores da literatura dramática do Rio Grande do Sul. Porto Alegre: FischerPress, 2014, p. 5)". pós-graduação (entre mestrado e pós-doutorado), minuciosos e extensos estudos (ao longo desses 12 anos) para, de certa forma, resgatar e revelar autores desse gênero que acabou se tornando "esquecido ou relegado a plano secundário" (FISCHER, 2014, p. 5). Até a publicação e o lançamento, no final de 2014, desse dicionário que compila, no seu total, 912 verbetes, entre autores e pseudônimo - "Hum Militar Avulso" (idem, p. 144), nascidos ou que desenvolveram e fomentaram o teatro no Rio Grande do Sul.

Dessa forma, o Dicionário de autores da literatura dramática do Rio Grande do Sul, editado de forma independente (a FischerPress é de propriedade do autor), corrobora para elucidar aspectos da literatura dramática, da história da literatura e da história do teatro. Nesse último aspecto, em especial, através de matérias de jornais e periódicos da época é possível verificar o tipo de recepção crítica que a peça teve quando montada, bem como características da sua encenação, por exemplo. A publicação ainda revela nomes desconhecidos e resgata outros tantos esquecidos, inclusive, rechaçando a ideia de que a dramaturgia teria sido pouco desenvolvida no Estado por causa da escassez de autores.

Fischer comprova justamente o contrário, já na sua dissertação de mestrado ${ }^{2}$, cujo período de estudo se restringiu ao século XIX, aponta para o registro de, aproximadamente, 660 textos, entre dramas, comédias e outras formas ou classificações teatrais, "dos quais em torno de 160 nos foram legados, por seus autores, na forma escrita" (FISCHER, 2014, p. 6). Levando-se em conta que a produção dramatúrgica em solo gaúcho começa, conforme o pesquisador, na década de 1830. Ademais, a obra suscita pertinentes contribuições para se perceber e entender, em níveis

2 Dissertação de mestrado intitulada: A literatura dramática do Rio Grande do Sul, do século XIX Subsídios para uma história, defendida no ano de 2003 no Programa de Pós-Graduação em Letras da PUCRS. 
social, histórico, econômico e cultural, as sociedades, seus costumes e quais conflitos ou temas dominavam em determinado tempo, por meio das representações construídas pelos dramaturgos nas suas peças teatrais.

Nesse sentido, faz-se plausível compreender, a partir da leitura e assimilação da história narrativa da literatura de David Perkins (1999), que a escolha do objeto de pesquisa - como o herói da história narrativa da literatura - de Fischer é a literatura dramática do Estado do Rio Grande do Sul. E é a trajetória desse herói - o gênero dramático - por meio de seus autores, que é narrada e constituída nas informações contidas nos verbetes. Conforme afirma Perkins (1999, p. 3), sobre esse herói:

Como toda a narrativa tradicional, apresenta uma entidade - ou herói sofrendo uma transição. Na história da literatura, o herói não pode ser uma pessoa - só um indivíduo social ou um assunto ideal podem protagonizá-la: eis o princípio do Iluminismo. Toma-se um momento de sua existência como início (as primeira batalhas) e um outro subsequente como ponto final (hoje).

No segundo momento, o estado interior ou exterior do herói não é o mesmo que foi no primeiro e o meio da narrativa é responsável por essa mudança; em outras palavras, mostra-se, dado o estado inicial dos acontecimentos, como o herói chegou ao final.

\section{Dicionário da literatura dramática do Rio Grande do Sul: autores, obras, temáticas abordadas ${ }^{3}$}

O Dicionário abrange os séculos XIX, XX e começo do século XXI, finalizando no ano de 2013. o período se estendia até o ano de 2011, quando Fischer concluiu e entregou o trabalho do Estágio Pós-Doutoral na UFRGS, mas, para essa edição final, a versão original foi atualizada e ampliada.

3 O Dicionário de autores da literatura dramática do Rio Grande do Sul (Porto Alegre: FischerPress, 2014) passará a ser mencionado, a partir desta seção, pela forma abreviada de Dicionário.
Na Apresentação da obra e na seção Notas Explicativas são explicitados procedimentos de pesquisa, objetivos do projeto e métodos para elaboração dos verbetes. Referindo-se ao dicionário como resultado de um "minucioso inventário" de autores da literatura dramática do passado e do presente, Fischer (2014, p. 10) relata que este "foi organizado com o objetivo maior de oferecer um painel abrangente da literatura dramática (...), capaz de servir de fonte para futuros estudos e pesquisas, especialmente, nas áreas das Letras e das Artes Cênicas". O pesquisador complementa a sua fala introdutória acrescentando que, dentre os objetivos, estava o fator do desmerecimento do gênero e a "crença" de sua pouca visibilidade:

Acreditamos que este dicionário não só possibilitará a ampliação da quantidade de gêneros passíveis de análise, em futuros estudos temáticos da nossa literatura, como também proporcionará a visualização da expressividade da dramaturgia gaúcha, contribuindo para a "desmistificação" da crença de que o Rio Grande do Sul não possui autores teatrais e nem uma literatura dramática que mereça ser considerada. (FISCHER, 2014, p. 8)

Portanto, foram incluídos os autores que contribuíram para a "construção de nosso patrimônio cultural no campo da dramaturgia" (FISCHER, 2014, p. 10), ainda que alguns desses tenham criado apenas um texto dramático ou mesmo os que não tiveram suas peças encenadas ou publicadas. Além das informações mencionadas em obras de historiografia literária nacional e regional, também foram coletados dados em: enciclopédias, índices e catálogos; nas peças publicadas, existentes nos acervos da Fundação Biblioteca Nacional, da FUNARTE, do Instituto Histórico e Geográfico do Rio Grande do Sul e das principais bibliotecas de Porto Alegre e do interior do Estado; nos textos datilografados ou digitados que integram os acervos da SBAT - Sociedade Brasileira de Autores Teatrais e do Teatro de Arena, de Porto Alegre; em jornais, periódicos e revistas; e, no caso 
dos dramaturgos mais recentes, na internet (ibidem). A fim de facilitar o acesso dos leitores aos textos escritos (publicados ou cópias manuscritas, datilografadas, digitadas), no final de cada verbete há indicação de onde podem ser encontrados para consulta. $O$ pesquisador reconhece que, apesar do empenho para o dicionário estar o mais completo possível, é plausível que ocorram equívocos e omissões de determinados autores ou obras.

Conforme os dados levantados por Antenor Fischer em seus estudos, ao se considerar as primeiras obras de historiografia da literatura brasileira, de Sílvio Romero (1888) e de José Veríssimo (1916), até se alcançar as mais recentes, como as de Massaud Moisés (2001) e Luciana Stegagno-Picchio (2004), dentre tantos estudiosos e estudiosas representativos(as), depara-se com somente dois autores de literatura dramática sul-rio-grandenses: Araújo Porto Alegre e Qorpo Santo. Conforme Fischer (2014, p. 6), “o primeiro, como se sabe, apenas nasceu no Rio Grande do Sul, tendo produzido toda a sua obra poética e dramática no Rio de Janeiro e no exterior; já o segundo só figura nas histórias literárias produzidas a partir da década de 1960, quando foi redescoberto". Erico Verissimo foi o único a mencionar outros dois autores de literatura dramática no século XX, em Breve história da literatura: Ernani Fornári e Álvaro Moreyra.

Com relação às historiografias regionais, são citadas as de João Pinto da Silva (1924), História literária do Rio Grande do Sul, e de Guilhermino Cesar (1956), História da literatura do Rio Grande do Sul. Na primeira são encontrados cinco "teatrólogos": Arthur Rocha, Joaquim Alves Torres, Damasceno Vieira, Pinto da Rocha e Abadie Faria Rosa, com a ressalva de Fischer (2014, p. 7) em informar que os três primeiros nomes estavam entre os que fundaram e mantiveram a Sociedade Partenon Literária. Cabe, aqui, distinguir o parágrafo em que o pesquisador relata como foi a apreciação do historiador João Pinto da Silva a respeito desses cinco nomes:
[Sic] Relativamente aos demais autores citados, nosso primeiro historiador da literatura informa apenas que as principais peças de Arthur Rocha (Anjo do sacrifício, Filho bastardo, José, Deus e a Natureza, além de outras mais) encontram-se reunidas em volume; que Damasceno Vieira legou-nos um "drama apreciável" (Arnaldo); e que Abadie Faria Rosa teve encenadas, com êxito, duas de suas peças: Nossa terra e Soldadinho de chumbo. Quanto a Joaquim Alves Torres, este mereceu apenas a citação de seu nome e a informação de que pertenceu ao Partenon Literário. Vale lembrar que dos cinco autores citados por João Pinto da Silva, Pinto da Rocha escreveu, no século XIX, apenas duas peças (ambas em Portugal): A padeira de Aljubarrota (1884) e $O$ dote do enjeitada (1885) e Abadie Faria Rosa, pelos dados que conseguimos coletar, nenhuma peça produziu no século XIX. (FISCHER, 2014, p. 7)

O segundo historiador, Guilhermino Cesar, trata da literatura dramática com mais "otimismo", ao dizer que os intelectuais de meados do século XIX em diante produziram em quantidade textos teatrais, mesmo que fosse "uma cena breve ou um prólogo dramático" (FISCHER, 2014, p. 7). Entretanto, assim como o seu antecessor, não destaca outros nomes, prestando ênfase à Arthur Rocha, e justifica que no teatro oitocentista gaúcho a produção dos românticos e naturalistas não criou "efetivamente um teatro válido como expressão inconfundível do meio" (FISCHER, 2014, p. 7).

Na sequência aparecem os nomes de Athos Damasceno que, em 1956, realizou "uma das mais importantes obras dedicadas ao teatro no nosso estado, só que com informações restritas à atividade dramática na capital" (FISCHER, 2014, p. 7), intitulada Palco, salão e picadeiro em Porto Alegre no século XIX - Contribuição para o estudo do processo cultural do Rio Grande do Sul; e Lothar Hessel, em 1999, que se dedicou ao levantamento de como foi o teatro no Rio Grande do Sul dos primórdios até aproximadamente as décadas de 1960 e 1970, com a obra $O$ teatro no Rio Grande do Sul, porém, nesse caso, o estudo, in loco, esteve mais voltado aos espaços físicos do que à literatura dramática em si. 
Apesar de considerar as primeiras experiências dramatúrgicas de relevo acontecidas no Estado a partir da década de 1830, Antenor Fischer (2014, p. 88). encontrou o registro do que viria a ser o primeiro texto teatral de um autor gaúcho, o jornalista e diplomata Hipólito José da Costa (nascido na Colônia do Sacramento em 1774, quando esta ainda era domínio português, criado em Pelotas, tendo iniciado os estudos em Porto Alegre): $O$ amor d'Estranja, de 1811. Dessa forma, Araújo Porto Alegre, destacado como 'pai' - pioneiro da literatura dramática do Rio Grande do Sul - acaba por perder a sua primazia.

O que, em hipótese alguma, retira o mérito do escritor (também botânico, poeta, arquiteto, pintor, professor, cônsul do Brasil na Prússia e em Portugal, entre outros cargos), organizador do Conservatório Dramático, tradutor de importantes peças como Electra, de Eurípides, Lucrecia Borges, de Victor Hugo, Cristina da Suécia, de Alexandre Dumas, autor de vinte e seis textos teatrais, entre comédias, prólogos dramáticos, óperas e dramas líricos, tragédias e dramas, sendo o primeiro de 1837, intitulado Prólogo dramático - "Uma alegoria política que teria sido representada no Teatro Constitucional Fluminense em 1836 na presença de Dom Pedro II, então com seus 12 anos" (FISCHER, 2014, p. 240). Dentre os pioneiros também podem ser citados os nomes de José Manuel Rego Vianna, que escreveu em 1836 Quarenta anos ou o negociante colono, e Manuel José da Silva Bastos, em 1849 escreveu $O$ castelo de Oppenheim ou o Tribunal Secreto.

No Dicionário consta a primeira autora de literatura dramática, Maria Clara da Cunha, jornalista, escritora, poeta e dramaturga: "Foi proprietária e redatora do jornal dominical $A$ grinalda, dedicado à defesa dos direitos das mulheres" (FISCHER, 2014, p. 92), que escreveu em 1887 duas peças: Uma lágrima derramada ou o ramo de violetas, drama, e A Flor do deserto, comédia. Outras duas autoras do final do século XIX representativas foram Andradina de Oliveira e Anna Aurora do Amaral Lisboa.
A jornalista, professora, escritora e líder feminista Andradina de Oliveira é autora de cinco textos teatrais, três dramas (em 1891), uma comédia (1899) e um drama histórico: Antônio Conselheiro, de 1902 - "Inspirado no episódio de Canudos. Estreado por amadores do 'Centro Artístico Furtado Coelho', de Porto Alegre, em 12 de novembro de 1902" (FISCHER, 2014, p. 217). A também professora, escritora e jornalista Anna Aurora do Amaral Lisboa é autora de seis textos teatrais e foi uma defensora da abolição da escravatura, entre os temas de suas peças estava a crítica à sociedade hipócrita da época. Conforme Fischer atesta no verbete da página 170, existem vários estudos e pesquisas sobre a vida e a obra dessa escritora.

Dois dramaturgos de destaque: Arthur Rocha e Qorpo Santo. O abolicionista Arthur Rocha foi também ator e comediógrafo, escritor e um dos fundadores do Partenon Literário. Devido à sua popularidade, salienta Fischer (2014, p. 260), “Das doze peças que escreveu, nada menos que cinco (os dramas $O$ anjo do sacrifício, O filho bastardo, José e Deus e a natureza, e a comédia Por causa de uma camélia...) fazem parte das mais representadas nos palcos gaúchos, no decorrer do século XIX". O pesquisador reproduz a fala de Guilhermino Cesar, de 1956, ao dizer que o dramaturgo teve grande êxito por caracterizar com precisão suas personagens, combater a escravidão com veemência, participando, assim, da luta de "seu povo", pela justiça social, o inconformismo e a desaprovação ao sistema social vigente (ibidem).

Qorpo Santo é um dos dramaturgos gaúchos mais lembrados, talvez o mais consagrado, além de ser apontado, em tom de reivindicação por alguns teóricos e críticos, como Alfredo Bosi, por exemplo, como o precursor do teatro do absurdo, muito antes dos europeus Luigi Pirandello, Alfred Jarry, Eugène Ionesco e Samuel Beckett (FISCHER, 2014, p. 245). José Joaquim de Campos Leão, poeta, teatrólogo e professor, propôs, inclusive, uma reforma ortográfica simplificadora para a língua portuguesa, como o próprio pseudônimo - o seu 'verdadeiro nome' - adotado por ele sugere. Identificado 
pelo nonsense e pelo tom subversivo, suas peças, quando postas em cena, dificilmente são representadas como foram escritas pelo autor (necessitando de adaptação), pois até mesmo a ação de atear fogo ao teatro está entre as suas rubricas.

Qorpo Santo deixou como legado dezessete textos teatrais, entre comédias, comédias satíricas, comédias de costumes, comédias dramáticas e tragicomédias. Mas foi necessário quase um século depois para que sua obra dramatúrgica fosse resgatada e reconhecida como tal. Qorpo Santo tornouse personagem do romance do escritor Luiz Antonio de Assis Brasil, Cães da Província, de 1988, e ainda hoje continua sendo montado pelo Brasil (com destaque para as montagens recentes do diretor carioca Moacir Chaves e sua companhia Alfândega 88, Labirinto, baseada em algumas comédias do autor, de 2011; e para a encenação gaúcha da diretora Inês Marocco, Santo Qorpo ou o louco da província, a partir do livro de Assis Brasil e das comédias de QS, de 2014). Assim como Fischer o faz em seu dicionário, reproduz-se, aqui, trecho de Alfredo Bosi:

[Sic] Suas comédias, lidas tanto tempo depois de escritas, beneficiaram-se de uma perspectiva moderna: o olho crítico, já treinado em Pirandello, em Jarry, em Ionesco, vê nonsense e absurdo como fenômenos ideológicos e estéticos válidos em si, além de testemunhos de resistência à lógica da dominação burguesa. E o aspecto descosido daquelas comédias, o efeito de delírio que às vezes produzem, a força do instinto que nelas urge, enfim o desmantelo do quadro familiar decoroso do Segundo Império que nelas se vê, tudo se presta a uma leitura radical no sentido de atribuir a Qorpo-Santo uma ideologia, ou melhor, uma contra-ideologia corrosiva, se não subversiva dos valores correntes, no teatro brasileiro do tempo. (BOSI, 1984, p 274. In: FISCHER, 2014, p. 245)

A partir da reunião dos verbetes no Dicionário e dos estudos anteriores de Antenor Fischer, é possível apontar certas tendências do teatro gaúcho oitocentista. Como as temáticas predominantes da desonra, do abolicionismo, da crítica à Igreja - especialmente aos jesuítas, do ideal republicano e relacionados à condição da mulher ${ }^{4}$. No que tange ao aspecto da desonra, as peças tratavam da falta de honra como causa do abandono da vida social das personagens, e os motivos principais para isso ocorrer eram a calúnia, a difamação, a perda da castidade de uma filha solteira, o adultério no casamento, em particular a traição feminina, e a falência dos negócios para os homens.

Numa época em que o conflito entre a Igreja e a maçonaria estava acirrado, a imprensa e o teatro serviram como importantes ferramentas de divulgação das críticas e opiniões contra a institucionalização junto ao Estado desse poder religioso, aqui representado, sobretudo, pelos jesuítas. 0 drama abolicionista também marcou presença entre os autores e autoras daquele período. Conforme matéria do jornal Zero $\mathrm{Hora}^{5}$, o abolicionismo não estava apenas entre os temas tratados, mas era, de certa forma, praticado, pois a renda de algumas encenações era revertida para a compra da liberdade de escravos. Assim como na busca pelo ideal republicano, a Sociedade Partenon Literário (em funcionamento de 1868 até 1880) teve destaque no debate pelo fim da escravidão. Acerca do ideal republicano, tal matéria relata:

o Partenon Literário estimulou o "teatro de tese", aquele utilizado para defender uma causa. Ao lado do abolicionismo, o ideal republicano estava presente em peças como Escrava e mãe (1880), de José Alves Coelho da Silva; Lucinda (1875), de Hilário Ribeiro; e Estrelas e diamantes (1874), de João da Cunha Lobo Barreto. Era o clamor pelo fim da monarquia em um momento no qual a corrupção imperava. Os gaúchos se juntaram à causa nacional depois que o sonho de uma República Rio-Grandense foi solapado. (ZERO HORA. 24 de janeiro de 2015)

${ }^{4}$ Com informaç̃̃es da matéria: Pesquisador recupera autores de teatro gaúchos esquecidos desde o século 19 do repórter Fábio Prikladnicki, publicada no jornal Zero Hora - edição online de 24 de janeiro de 2015.

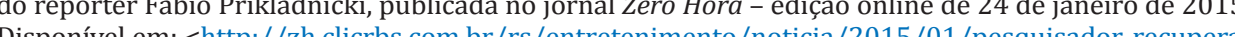
sador-recupera5 Idem. 
Outro fator relevante foi a constatação da escolha, por boa parte dos autores e autoras da época, pelo gênero comédia. De acordo com a matéria de Zero Hora, cerca de um terço das peças correspondiam ao gênero, considerando, dentre as publicadas, a quantia de cinquenta, sendo, dessas, dezessete de autoria de Qorpo Santo, como dito acima. O enredo das comédias estaria baseado em conflitos, enganos, sentimento de ciúmes, em situações como namoros e casamentos. Uma das influências constante e perceptível era a do dramaturgo francês Molière ${ }^{6}$. Para além da bipartição entre drama e comédia, o teatro ocidental começa a sofrer mudanças decisivas e que vão acabar repercutindo na literatura dramática e no próprio fazer teatral dos e nos palcos gaúchos.

Do final do século XIX para o começo do século XX, com a crise do drama absoluto (o drama 'clássico' - 'sério' - 'burguês' - preconizado por Diderot e Voltaire no século XVIII) e sua consequente superação, o surgimento de dramaturgos como Henrik Ibsen, August Strindberg, Gerhart Hauptmann, Maurice Maeterlinck e Anton Tchekhov, e posteriormente o teatro épico de Bertolt Brecht, é que o sentido moderno de teatro começa, com experimentações formais, mudanças estilísticas, fragmentações (sem encadeamento causal), relativização de tempo e espaço, transformações nas relações intersubjetivas das personagens.

De acordo com o teórico do teatro, Peter Szondi (2011), essa mudança histórica pode ser entendida como um processo de consolidação, através da forma e também do conteúdo, ao romper com a forma antiga, ainda que as temáticas desenvolvidas no percurso do drama moderno se mantivessem, em sua maioria, as mesmas do drama clássico. Foi nesse momento de transição que surgiram os experimentalismos. Com isso, as formas dramáticas passaram a assumir recursos de outras poéticas, como elementos da épica e

${ }^{6}$ Idem. da lírica, especialmente, pela utilização de personagens-narradores épicos, encadeamento de cenas com fragmentação e mobilidades temporais, conforme dito antes.

Segundo Jean-Pierre Sarrazac, organizador do Léxico do drama moderno e contemporâneo (2012, p. 33), a crise da forma dramática, deve ser entendida através de quatro crises diferentes: a crise da fábula, "déficit e pulverização da ação", permitindo o surgimento das atuais dramaturgias do "fragmento", do "material", do "discurso"; a crise do personagem, que ao ser apagado, liberta a "figura", o "declamador", "a voz"; a crise do diálogo, que propicia a forma de um teatro cujos conflitos inserem-se no próprio âmago da linguagem, "da fala"; e a crise da relação palco-plateia, com o "questionamento, no - e a partir do - texto mesmo, do textocentrismo".

O estilhaçamento do diálogo nos dias de hoje, seu caráter polifônico ou, ao contrário, coral, eliminando as diferenças entre os enunciadores, deve-se amplamente ao terremoto introduzido pela conversação no campo da fala teatral. A multiplicação das vozes esparsas e não identificadas, e a importância dada à fala ambiente derivam de um primeiro modelo. Outros modelos afirmam-se com veemência na segunda metade do século XX. Alguns dramaturgos acolhem a fala comum em enunciados bem sucintos. A apreensão de réplicas esparsas no cotidiano revela, pelos efeitos da montagem, formas de interação inesperadas entre enunciadores-personagens que, não obstante, não manifestam nenhum compromisso em suas declarações. (SARRAZAC, 2012, p. 99)

Dessa forma, o teatro que antes era encarado como 'textocêntrico', com predomínio do texto (e, pode-se dizer, do 'dramaturgo de gabinete' - aquele que apenas se envolvia na escrita dramatúrgica), passa a ser um teatro de encenador, com forte presença do encenador - o diretor - e relevância ao trabalho do ator como também autor, colaborador e construtor do espetáculo. É claro, ressalva-se que, em vários períodos históricos, o dramaturgo também foi o encenador e/ou ator da companhia como Molière e Shakespeare, por 
exemplo. E, aqui no Rio Grande do Sul mesmo, tem-se o caso de Arthur Rocha, já citado, também ator, chegou a interpretar um dos papéis de herói negro no drama José, inclusive.

É nesse sentido que o Dicionário acompanha e reflete tais mudanças, quando apresenta nomes importantes como Álvaro Moreyra e Carlos Carvalho. Álvaro Moreyra (homenageado em uma das salas de teatro municipais de Porto Alegre) fundou o grupo Teatro de Brinquedo, no Rio de Janeiro, com nomes essenciais do teatro brasileiro como Bibi Ferreira e Joracy Camargo, além de dirigir a Companhia de Arte Dramática, prestando serviço para o governo em espetáculos a nível nacional. Álvaro Moreyra escreveu treze textos, algumas obras em parcerias, entre comédias, teatro de revista, musicais, esquetes e pantomimas (FISCHER, 2014, p. 202).

Carlos Carvalho, ator, professor, funcionário público, escritor, diretor de teatro (também empresta seu nome a uma sala da capital gaúcha), é considerado um dos mais representativos dramaturgos das décadas de 1970 e 1980, "que encontrou no drama cotidiano urbano as fontes de criação para o seu teatro de denúncia e resistência” (FISCHER, 2014, p. 70). Sua produção é vasta e conta com trinta obras. Outro nome de evidência é o de Ivo Bender, que foi professor do Departamento de Artes Dramáticas (DAD) da UFRGS, tradutor, escritor e dramaturgo, sua trilogia infantil $O$ macaco e a velha foi encenada nos Estados Unidos e também radiofonizada na Alemanha. Além da sua produção de quarenta peças teatrais, Bender escreveu livros teóricos sobre o teatro. Nas palavras de Antonio Hohlfeldt, crítico de teatro gaúcho (atualmente no Jornal do Comérico), Ivo Bender seria o primeiro dramaturgo contemporâneo de importância no Estado, compartilhando o posto com Carlos Carvalho (FISCHER, 2014, p. 39).

Em seu Dicionário, Antenor Fischer apresenta uma variedade de nomes de dramaturgas e dramaturgos contemporâneos(as) (serão citados na sequência) que, podem, por sua vez, contemplar e evidenciar, nos seus trabalhos, o sentido múltiplo e as características plurais da dramaturgia atual. A maioria deles e delas também são atores e atrizes, diretores e diretoras, fundadores(as) de companhias e grupos, ressaltando, assim, o fazer teatral stricto sensu, no grau de coletividade - da pesquisa à escrita, da produção à encenação, da atuação à iluminação, etc. É posto que, na contemporaneidade, a discussão de dramaturgia como texto literário (gênero dramático), podendo estar separado ou distinto do espetáculo ou da encenação, ou, por outro lado, de natureza apenas teatral, está ultrapassada. A palavra dramaturgia, para e no teatro, já adquiriu conotação ampla, deixando de restringir-se ao próprio texto e ao gênero, mas englobando e significando práticas, desenvolvimentos, funcionamentos, ou seja, em termos gerais, 'poéticas', como, por exemplo, a dramaturgia do encenador ou diretor, a dramaturgia do ator: a poética de um autor (também diretor, ator, dramaturgo).

Bem como, os conceitos-práticas de drama - dramático - teatro teatralidade(s) - peça - espetáculo - artes cênicas - artes dramáticas ${ }^{7}$ - com a conexão (incorporação e integração recíprocas) das artes performáticas, do universo das comunicações, das artes visuais, da música. Ainda assim, cabe, aqui, uma reflexão acerca de dramaturgia em relação ao texto (verbal: escrito e não ao texto verbal: oral, em e da cena), atualmente, mostra-se difícil encontrar pesquisas, tanto em âmbito das letras, quanto do teatro, que escolham e destaquem esse como objeto de investigação. Ao que corrobora o apontamento de Fischer (2014) sobre o gênero (literatura dramática) estar relegado ao "plano secundário". Com isso, nota-se, nas poucas pesquisas em curso ou disponíveis, que, em certos casos, o pesquisador ou a pesquisadora

7 Um possível paralelo, quiçá, possa ser estendido à literatura, no que concerne aos próprios conceitospráticas de literatura e literaiedade(s), texto e textulidade(s), e também aos múltiplos e diversos práticas de literatira e literariedade(s), texto a textualidade(s), e tambén aos mútiplos e diversos de suportes e plataformas (e-books, livros digitais, livro-objeto), por exemplo. 
opta por tratar o objeto texto teatral escrito como dramatúrgico ao invés de texto dramático ${ }^{8}$.

A respeito da dramaturgia na contemporaneidade, Sílvia Fernandes (2010, p. 153), situa-a no campo da diversidade, evitando, desse modo, qualquer espécie de generalização. A dramaturgia contemporânea pode, segundo ela, estar assentada sobre as regras dos "playwriting" ou estruturada como "storyboard" de cinema, mesclando padrões de ação e diálogo ou justapondo monólogos, cuja temática, a partir dos problemas atuais, é tratada de forma realista ou metaforizada em temas abstratos, mas não deixa de transformar a relação do texto (e à tríade autor-ator-público) com o real, a representação do real, e não sua simples reprodução (como se pretendia num teatro real-naturalista). A autora complementa:

0 resultado da apropriação da teatralidade pela dramaturgia mais recente é que o texto literário ganhou novo estatuto. 0 dramático ainda se conserva no modo de enunciação, na construção dos diálogos, monólogos ou narrativas e, algumas vezes, no desdobramento das personagens. Mas a qualidade teatral deixa de ser medida pela capacidade de criar ação. Agora teatral pode ser apenas espacial, visual, expressivo no sentido da projeção de uma cena espetacular. Paradoxalmente, é teatral um texto que contém indicações espaço-temporais ou lúdicas autossuficientes. Os textos do dramaturgo francês Bernard-Marie Koltès, por exemplo. É interessante observar como em suas peças a circulação da palavra auxilia a construção de estratégias espaciais complexas. (FERNANDES, 2010, p. 163)

\footnotetext{
${ }^{8}$ Acerca das pesquisas e investigações em dramaturgia e texto dramatúrgico é possível citar, dentre outros, três exemplos recentes: a dissertação de mestrado no Programa de Pós-Graduação em Artes Cênicas (PPGAC) da UFRGS de Nayara Macedo Barbosa de Brito, intitulada Formas de ser um, de ser Só. Modos de sentir da dramaturgia brasileira contemporânea, defendida em 2015; a dissertação de mestrado em Teatro da Universidade do Estado de Santa Catarina (UDESC) de Patrícia dos Santos Silveira, intitulada Dramaturgia da fala: escrita e oralidade na construção do texto teatral (2012) e pesquisa de doutorado em curso de Patrícia (também dramaturga, atriz e diretora de teatro) na área de Escrita Criativa na PUCRS, intitulada Poema a céu aberto: corpo e metáfora em textualidades
performativas.
}

Dessa forma, Sílvia Fernandes (2010) incorpora ao seu discurso o argumento do teórico Patrice Pavis, segundo o qual o texto teatral está definido pelo critério elocutório, ou seja, tudo o que se fala em cena constitui o texto de teatro. Outro traço é a integração de diferentes estilos de narrativa, como romances, poemas, roteiros cinematográficos, excertos de obras variadas (literárias, audiovisuais, musicais), fragmentos de falas que podem parecer desconexas, num primeiro momento, porém, estão a serviço de uma dramaturgia cênica do próprio diretor ou dos atores da peça. Fernandes (Idem) cita o teórico da Escola de Praga, Jiri Veltruský, para quem o drama não deixa de ser uma obra literária por agregar elementos e componentes de teatralidade, como a performance, nesse caso:

Talvez essa tenha sido uma das mudanças (a confluência da literatura com a teatralidade para gerar um sentido aberto e oportunizar ao público completar a lacuna) mais radicais da relação texto/cena no teatro contemporâneo. Para entendê-la, não é preciso voltar à discussão sobre a natureza literária ou teatral do texto dramático. Jiri Veltruský, teórico da Escola de Praga, considera a discussão inútil. Observa que sem dúvida o drama é uma obra literária e, enquanto tal, pode ser simplesmente lido ou usado como componente da performance, como faz Robert Wilson com os textos de (Heiner) Müller. A diferença está no tipo de teatro que se pratica e, em última instância, vai determinar a escolha e o uso que se faz do texto. Algumas formas teatrais contemporâneas, por exemplo, preferem os textos líricos e narrativos ao drama, pois pretendem que a escritura cênica entre em relação com a literatura como um todo, e não apenas com o gênero dramático. (FERNANDES, 2010, p. 158)

Dentre os dramaturgos encenadores e/ou atores, diretoras e/ou atrizes, contemporâneos(as) mencionados na obra de Fischer e em atividade, tanto no Rio Grande do Sul como no Brasil e exterior, ressaltam-se os nome de: Luciano Alabarse (coordenador e curador do Festival Internacional Porto Alegre em Cena), Luiz Paulo Vasconcellos, Paulo Flores (um dos fundadores da Terreira da Tribo e mantenedor da Tribo de Atuadores Oi Nóis Aqui 
Traveiz), Roberto Oliveira (fundador do Depósito de Teatro), Renato del Campão, Camilo de Lélis (fundador do grupo Faces e carretos), Hamilton Leite (um dos fundadores do Oigalê Cooperativa de Artistas Teatrais), Adriane Mottola (fundadora da Cia Teatro di Stravaganzza), Marcelo Restori (um dos fundadores do grupo Falos \& Stercus), Daniel Colin (fundador do Teatro Sarcáustico), Alexandre Vargas (um dos fundadores do grupo Falos \& Stercus e coordenador e idealizador do Festival Internacional de Teatro de Rua de Porto Alegre), Marcelo Adams (um dos fundadores do Teatro ao Quadrado), Sandra Dani, Nelson Diniz (um dos fundadores da Incomode-te), Vanise Carneiro, Júlio Conte (um dos fundadores da Cômica), Patsy Cecato (também fundadora da Cômica), Deborah Finocchiaro, Zé Adão Barbosa (fundador da Casa de Teatro), Márcia do Canto, João Carlos Castanha (ator e performer).

Destacam-se os trabalhos de teatro infantil de Claudio Levitan, Viviane Juguero (Bando de brincantes), Raquel Grabauska (Cuidado que mancha) e Ronald Radde (Teatro Novo). Além do teatro voltado para o público adolescente (infanto-juvenil) de Vanja Ca Michel: o espetáculo de sua autoria, Adolescer, estreou em 2002 e continua sendo apresentado até hoje, com sucesso de público e crítica, conforme indica Fischer (2014) na reprodução da coluna intitulada A dura experiência da adolescência, do crítico teatral Antonio Hohlfeldt, na edição do Jornal do Comércio de 7, 8 e 9 de março de 2003:

A atriz e diretora Vanja Ca Michel teve uma ideia brilhante, que se transformou num espetáculo inédito e numa das peças mais bacanas já apresentadas no estado. Depois de 20 anos ministrando aulas de teatro para adolescentes em escolas da capital gaúcha, e vendo a necessidade que estes jovens tinham de falar sobre sua adolescência: Afinal, o que está acontecendo comigo? Por que tantas dúvidas? Por que, de repente, este conflito entre pais e filhos? Enfim, todas as angústias e sonhos desta que é uma das etapas mais bonitas de uma pessoa que está em fase de crescimento e das escolhas para tornar-se um adulto feliz. (HOLFELDT. In: FISCHER, 2014, p. 194)
O teatro com temática social e de luta pela causa negra de Jessé Oliveira (Grupo Caixa-Preta) merece distinção. O dramaturgo Júlio Zanotta e sua representativa obra de vinte peças teatrais também está entre os verbetes. Bem como, o trabalho com circo e dramaturgia de espetáculos circenses do diretor Dilmar Messias, do Circo Girassol. Os novos nomes da dramaturgia como Diones Camargo, Felipe Vieira de Galisteo e Fernando Kike Barbosa. Jair Kobe e a criação de Guri de Uruguaiana em formato show cômico. Entre os escritores e jornalistas reconhecidos que escreveram para teatro encontram-se os verbetes de: João Simões Lopes Neto, Erico Verissimo, Luís Fernando Verissimo, Mario Quintana, Lila Ripoll, Caio Fernando Abreu, João Gilberto Noll, Carlos Nejar, Josué Guimarães, Barbosa Lessa, Lya Luft, Cíntia Moscovich, Caco Barcellos e Juremir Machado da Silva.

Aponta-se para uma curiosa questão, a da quantidade de textos criados: enquanto o empresário, ensaiador, diretor e funcionário da Secretaria de Guerra e Inspetor da Polícia Marítima, Agostinho José Marques Porto, até o momento de sua morte, em 1934, escreveu mais de cem peças teatrais, das quais, sessenta e cinco constam o registro no Dicionário, sendo, talvez, o dramaturgo gaúcho com a obra mais extensa (FISCHER, 2014, p. 233-238). Do outro lado, com apenas uma obra publicada, mas, sob um fato igualmente notável, está o professor de literatura e filósofo Pedro Mandagará Ribeiro: "Quando publicou a peça abaixo tinha apenas 10 anos de idade e era estudante da 5. a série da Escola Estadual Otávio de Souza, de Porto Alegre. 1) A lenda de Perseu, peça em três atos, 1993. Publicada em A lenda de Perseu. Porto Alegre: Gráfica CEUE, 1993" (ibidem, p. 258).

\section{Considerações finais}

Como David Perkins (1999) estabelece na história narrativa da literatura a ideia do herói, que esse tem um ponto inicial (as primeiras batalhas), um 
ponto de chegada (o momento presente), e acontece uma transformação no meio dessa jornada, evidenciando que, em seus estados interior ou exterior, ele não pode mais ser aquele do original, assim é possível correlacionar a história da literatura dramática, no que tange à história da literatura eà história do teatro, consequentemente, como o herói acompanhado nos verbetes do Dicionário. Antenor Fischer destaca esse herói, particularizando-o, como a literatura dramática do Rio Grande do Sul e identificando como ponto inicial o século XIX, em torno da década de 1830, e como final o século XXI, o ano de 2013.

Muitas transformações dão conta das reviravoltas no meio da caminhada desse herói, dos textos teatrais oitocentistas com temática abolicionista, sobre a questão da desonra, dos conflitos da Igreja com a maçonaria, do ideal republicano, da situação da mulher, das comédias sobre casamentos e adultérios, romances e aventuras; até se alcançar a ruptura de um modelo "textocêntrico", da tendência real-naturalista, das crises da personagem e do diálogo, para se adentrar no teatro moderno de encenador, as peças criadas e escritas pelos próprios diretores e /ou atores; e, enfim, cruzar a linha de chegada, ou permitir que o pano desça e o espetáculo se encerre, com o teatro contemporâneo e as novas linguagens, teatralidades e performances (no denominado teatro pós-dramático). Dessa forma, o herói é mostrado em consonância com as mudanças do gênero dramático, da dramaturgia, do fazer teatral do Ocidente, ou seja, a repercussão do que aconteceu em nível macro está refletida nas peças escritas, publicadas e encenadas nos palcos gaúchos.

O Dicionário de autores da literatura dramática do Rio Grande do Sul compreende 912 verbetes, e é através desses nomes e das suas obras que surgem as possibilidades de análise e interpretação das características dos textos, dos estilos de encenação, da recepção crítica, das temáticas abordadas, da produção de seus autores, das temporadas e duração dos espetáculos, dos elencos que participaram, de prováveis motivos ou fatores de não-encenações (os dramaturgos que ficaram apenas no papel), do contexto e da situação das sociedades representadas nas peças, dos elementos econômicos, culturais e sociais de diferentes períodos históricos. Isto é, podem ser elencadas inúmeras possibilidades de hipóteses de investigações, além de auxiliar e favorecer pesquisas e estudos a partir desse material.

\section{Referências}

FERNANDES, Sílvia. Teatralidades contemporâneas. São Paulo: Perspectiva, 2010.

FISCHER, Antenor. Dicionário de autores da literatura dramática do Rio Grande do Sul. Porto Alegre: FischerPress, 2014.

GUINSBURG, Jacó. Da cena em cena: Ensaios de teatro. São Paulo: Perspectiva, 2004.

PERKINS, David. História da literatura e narração. Cadernos do Centro de Pesquisas Literárias da PUCRS, Porto Alegre, v. 3, n. 1, mar. 1999. Série Traduções.

SARRAZAC, Jean-Pierre (Org.). Léxico do drama moderno e contemporâneo. São Paulo: Cosac Naify, 2012.

SZONDI, Peter. Teoria do drama moderno (1880-1950). São Paulo: Cosac Naify, 2011.

UBERSFELD, Anne. Para ler o teatro. São Paulo: Perspectiva, 2010.

ZERO HORA. Pesquisador recupera autores de teatro gaúchos esquecidos desde o século 19. Edição online: 24 de janeiro de 2015. Disponível em: <http://zh.clicrbs.com.br/rs/ entretenimento/noticia/2015/01/pesquisador-recupera-autores-de-teatro-gauchosesquecidos-desde-o-seculo-19-4686677.html>. Acesso em: abr. 2015.

Recebido em 21/04/2015

Aceito em 23/09/2015. 